\title{
乳牛における血漿ブドウ糖・乳酸・脂質・尿素 濃度の泌乳期間中の推移
}

\author{
佐藤 博・花坂昭吾・今村照久
}

東北農業試験場，盛岡市 020-01

(1981. 2.8 受付)

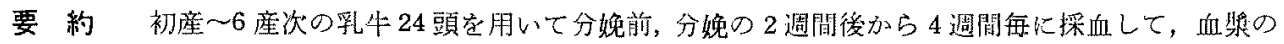
ブドウ糖・乳酸・遊踓脂肪酸 (FFA)・トリダリセライド (TG)・総コレステロール (T・Ch) と尿菜濃

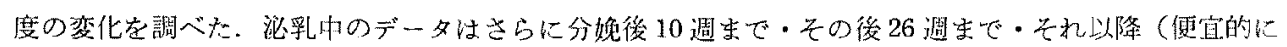
泌乳初期・中期・後期とする）に分けて比較した．ブドウ糖濃度は 2 週間後に低下した例もあったが，

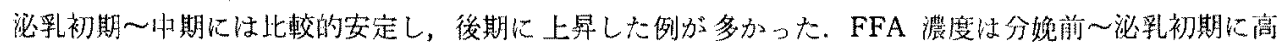
く，その後低下した．TG 濃度は泌乳開始によって急激に低下し，泌乳期閒中低かった．また $\mathrm{T} ・ \mathrm{Ch}$

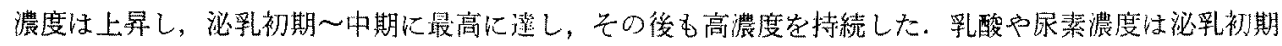
に低下する傾向宗した，産次による差が著しかっったのは泌乳中期〜後期の $\mathrm{T} ・ \mathrm{Ch}$ 浱度であり，初座 で高かった，乳量は 3〜4座次の牛で多かった。

日蓄会報, $52(9)$ : 653-658, 1981
\end{abstract}

釈牛の分婏や泌乳に上もなう代謝機構や血液成分の変 化については多くの研究があり, 最近の BAUMAN and CURRITE ${ }^{1)}$ の総説に詳しい，年の変化には概して分婏後 の比較的短期間汇みられるすのと泌乳中，長期にわたっ て持続する栥化とがある．前者についてはその変動が急 激であるため獣医臨床・試験研究の両面から注目され， 分婏前後の代謝機搼や血液成分の变化については多くの データが蔳積されている。ところが，後者に関して注比 較的緩慢で，泌乳中，長期にわたるため実験上の制約も 多く，不明の点毛多い：また乳牛の代謝機構や血液成分 に対する年龄あるい梳次の影響も解明されていない， 本研究で注周年サイレージ給与条件下の初産〜6 産次の 乳牛を用いて分婏前そして泌乳中に定期的に採血し, 乳 期や産次と血墏成分の関係を調べた。

\section{材料および方法}

1978 年 2 月 1979 年 12 月に東北農業試験場で分婏し た初座〜6次のホルスタイン種の乳牛 24 頭を供試した。 全期䦎，粗飼料として牧草・大麦・トゥモロコシを材料 としたサイレージを周年給与した．それらの発酵状態や 水分含量も一棁でないため，1 日の給与量も $18 \sim 45 \mathrm{~kg}$ と変動したが，概水飽食に近い状態であった，每日7時 と 16 時に售乳し(摍乳室), 乳量の約 $1 / 3$ 量の濃厚飼料 を朝・夕の2 回に分けて給与した。朝の㵠乳後はパドッ
クに放飼し，14 時ごる上記のサイレージ給けのため畜 舎に収容して䍿乩なでスタンチョンにけい養した（夕刻

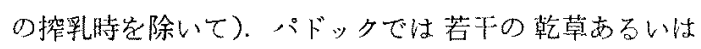
稲ワラサイレージ数 $\mathrm{kg}$ を与克た、乳期により差はある が，全期間定通じて粗飼料からの乾物掑取量の平蜴は約 60〜70\%であった。

牛の泌乳成績や体重などを表 1 に示した，分婏後の体 重は後産排出直後の値であり，その後1力月每に体重と 乳成分を測定し，最低体重と期間中の乳成分の平均を示 した．実験期間中に受胎しない牛が 4 頭あった。

分娩前に $1 \sim 3$ 回, 分婏 2 週間 後加 4 淍閒每に乾乳 前まで (50週以後怔省略) 原則としてサイレージ給与の ためパドックから畕舎に牛を収容した直後に採血した (ヘパリン使用)。血漿を分離し，一部は乳酸分析のため 直ちに $10 \%$ トリタロル酘酸で除蛋白して，ての上清と 残り血漿も谏結保存した。

後曰，これらを解凍して数時間以内にブドウ糖を醉素 法2) (New-Glucostat; Worthington 製, または Blood Sugar-GOD-Test; Boehringer 製), 乳酸を BARKERSUMMERSON 法3)，避雅脂肪酸 (FFA) ITAYA-U1 浩4) (NEFA テスト; 和光緦薬製), トリグリセライド (TG) と総コレステロール $(\mathrm{T} \cdot \mathrm{Ch})$ をアセチルアセトン钦) 打よび酵素㳂6) (Triglyceride B-test; Cholesterol Ctest；とも和光純薬製）によって分析したまなた Di- 
传滕・花坂 - 今树

Table 1. Mean values in lactation property and body weight in the cows

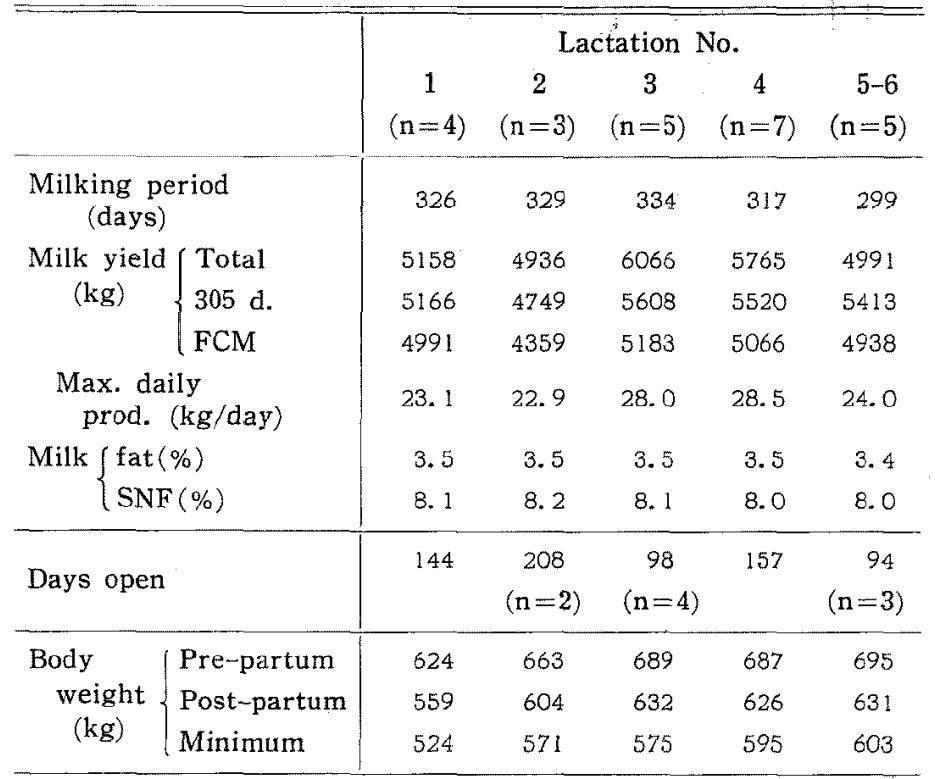

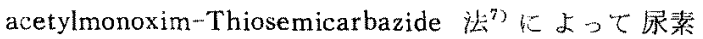
濃度定調べた。

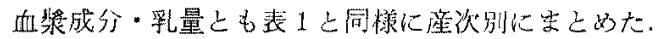
乳量以探血当日とその前後 3 日間（計 7 日間）の平均值

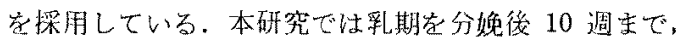
その後 26 週までとそれ以降に分けて（便宜的に泌乳初 期・中期・後期とする) 検討を加えた.

\section{結果}

实験期間中に 2 3 日間の食欲不振（食演のため）辛2 頭，乳房炎が2頭あったが，採血時点とは離れており次 回採边時に怔常に筫していた，泌乳末期（265日）に 後肢跛行のため廃用にした 1 例では特に乳量の減少はな かったが，その時点の血漿ブドウ嵣や乳酸浱废がかなり

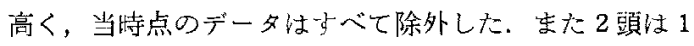

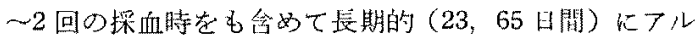
コール不安定乳を呈したが，その時の血獎成分にはその

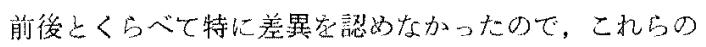
データは除かな加っだ。

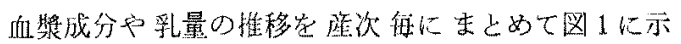
した. 血漿成分はさらに分婏会と泌乳犼・後期に

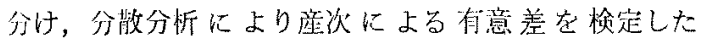
(表 2).

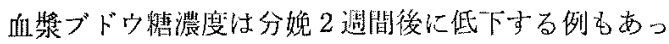
たが，汹乳初・中期には変動が小さく，概承 $60 \mathrm{mg} / \mathrm{d} l$
前後であった。徯期には変動が大きくなっていた，乳酸 濃度怯泌乳初期に低下与る例が多かったが．個体差が大 きく, 常に $15 \mathrm{mg} / \mathrm{d} l$ 以上走示した個体や常に $5 \mathrm{mg} / \mathrm{d} l$ 以下の俔体があった. 5〜6歴次の牛で乳酸濃度が高い傾 的にあった。尿素濃度は 2 週間後に低下寸る例が多く， 特に2 産次の牛では泌乳初期に低值が続いた。

TG 濃度は泌乳開始によって急激に低下し，その後功 っくり上昇する傾句にあったが，分婏前の值には回復し なかった。 反对に $\mathrm{T} \cdot \mathrm{Ch}$ 濃度は泌乳中に上昇して 10〜

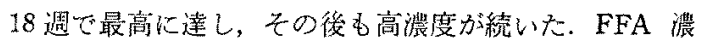
度は分婏前〜泌乳初期に高く，その後低下して泌乳中〜 後期にはほとえど同レベルであった。これら脂筫源度に は産次による差があり，泌乳中〜後期の $\mathrm{T} ・ \mathrm{Ch}$ 濃度は 初産の牛で特に㗬く，同期の TG P FFA 濃度は 5 6 産次の牛で低かった。また，初痖の牛では泌乳初期の FFA 濃度が他の牛よりも宮かっだ。

\section{考察}

血液成分の推移艺夕る場会，日内变動户季節的影響に

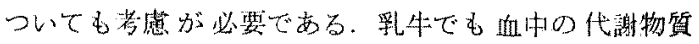
(metabolite)やホルモン祳度には採食にともなう変化な ども会めて日内变動がみられる ${ }^{8-10)}$. 本策験のデータで あ日内变動による影響を否定できないが，常に同じ時刻 に括ける血液試料のデータとして比較・検討して大過な いと䍐われる. 次に，ホルモンの分泌や感受性に打りる 
䟕牛の血獎成分の变化
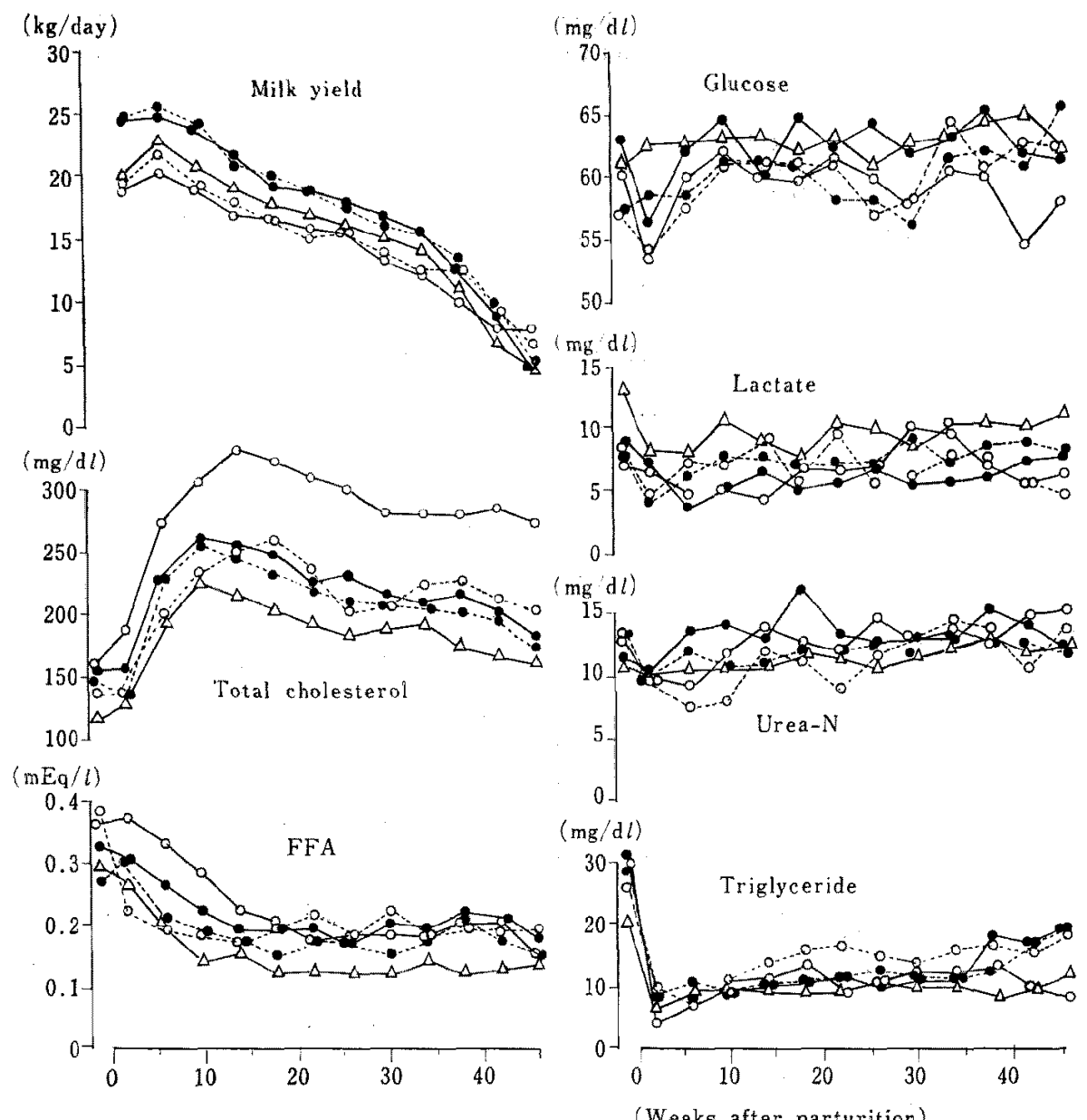

Fig. 1. Means of plasma metabolite levels and milk yield at various stages of lactation $0-01$ st lactation $(n=4)$. $\quad 0 \cdots 02$ nd lactation $(n=3) . \quad-3$ rd lactation $(n=5)$. -... 4 th lactation $(n=7) . \quad \Delta \sim 5 \sim 6$ th lactation $(n=5)$.

季節差は乳牛でも知られているが泣，血中の代謝物質の 濃度に対する季節の影響は充分に明らかでない，牛群の

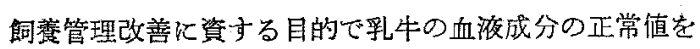
求好研究がイギリス等で大規模に展開され(Metabolic Profile Test)，それによると血清尿素やその他の成分

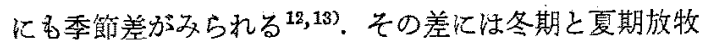
時のような飼料案件の差異による影響が大きいともいか

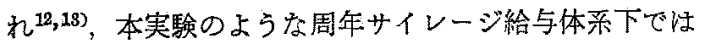
季節差往ある大きくないと考党られよう。

分婏や泌乳開始にともなう血漿ブドウ糖・乳酡・ FFA・TG やホルモン浱度の变化には相互に深い関俰が あり, HART ら ${ }^{14,152}$ の優れた研究がある. 泌乳開始によ ってプドウ楉・乳酸濃度の低下と FFA やケトン体濃度 の上开がみられ，ホルモンではインスリンや甲状腺ホル
モン $\left(T_{4}\right)$ 浱度が低下して, 戍長ホルモン $(\mathrm{GH})$ 濃度 が上昇するといわれる ${ }^{14)}$.

しかし，泌乳初期のブドウ糖濃塺関しては，下降 ${ }^{12}$ ${ }^{16-18)}$ ，不変 ${ }^{199}$ ，上䒜 ${ }^{20)}$ が報告されている。本実唤でも 2 週間後のプドゥ糖浱度が分埃前にくらべて $5 \mathrm{mg} / \mathrm{d} l$ 以 上の変化を示したものに，下降が 8 例，上昇が 4 例あ。 た.ブドウ糖濃度のこの変化と乳量には特に関連はなか った. BLOM and HALSE ${ }^{21)}$ によると泌乳初期よりる中〜 後期にブドウ糖濃度が高いといかれ，本実験であ初産の 牛を除き同様の傾们がみられた（表 2).

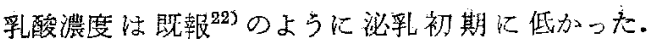

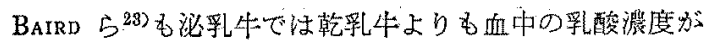
低く，肝による乳酸の利用克淮を報告している，淰乳初 期には糖新生のため多くの乳酸が糖前駆物質として使わ 
㭠藤・花坂・今村;

Table 2. Mean levels of plasma metabolites at pre-, 2-10, 14-26 and $30-46$ weeks after calving and those differences among lactation numbers of the cows

\begin{tabular}{|c|c|c|c|c|c|c|c|}
\hline & \multirow{2}{*}{$\begin{array}{l}\text { Weeks } \\
\text { post } \\
\text { partum }\end{array}$} & \multicolumn{5}{|c|}{ Lactation No. } & \multirow[b]{2}{*}{ Dif. $^{1}$} \\
\hline & & 1 & 2 & 3 & 4 & $5-6$ & \\
\hline \multirow{4}{*}{$\begin{array}{l}\text { Glucose } \\
(\mathrm{mg} / \mathrm{d} l)\end{array}$} & pre- & 60.3 & 57.1 & 62.9 & $57.9^{-}$ & 61.2 & \\
\hline & $2-10$ & 58.5 & 57.5 & 61.0 & 59.4 & 62.8 & \\
\hline & $14-26$ & 60.3 & 60.1 & 62.9 & 59.6 & 62.6 & \\
\hline & $30-46$ & 58.7 & 61.6 & 62.9 & 61.0 & 63.3 & \\
\hline \multirow{4}{*}{$\begin{array}{c}\text { Lactate } \\
\text { (11) }\end{array}$} & pre- & 7.1 & 7.8 & 8.7 & 7.4 & 13.2 & \\
\hline & $2-10$ & 5.3 & 6.1 & 5.2 & 5.7 & 9.0 & \\
\hline & $14-26$ & 6.1 & 7.4 & 5.9 & 6.8 & 9.1 & \\
\hline & $30-46$ & 8.0 & 6.2 & 6.1 & 8.2 & 9.9 & \\
\hline \multirow{4}{*}{$\begin{array}{c}\text { Urea-N } \\
(11)\end{array}$} & pre- & 12.8 & 13.5 & 12.9 & 11.4 & 11.1 & \multirow{4}{*}{ * } \\
\hline & $2-10$ & 10.2 & 8.3 & 12.6 & 10.6 & 10.7 & \\
\hline & $14-26$ & 13.3 & 10.9 & 13.9 & 11.8 & 11.1 & \\
\hline & $30-46$ & 13.4 & 13.0 & 13.5 & 12.3 & 12.1 & \\
\hline \multirow{4}{*}{$\begin{array}{c}\text { Trigly - } \\
\text { ceride } \\
\text { (1) }\end{array}$} & pre- & 28.7 & 25.7 & 30.9 & 29.1 & 20.6 & \multirow{4}{*}{$\begin{array}{l}* * * \\
* * *\end{array}$} \\
\hline & $2-10$ & 7.5 & 9.1 & 8.6 & 10.1 & 8.6 & \\
\hline & $14-26$ & 11.1 & 15.1 & 10.1 & 11.0 & 9.7 & \\
\hline & $30-46$ & 11.9 & 15.9 & 14.6 & 14.2 & 10.0 & \\
\hline \multirow{4}{*}{$\begin{array}{c}\text { Choles - } \\
\text { terol } \\
(11)\end{array}$} & pre- & 157 & 137 & 152 & 145 & 115 & \multirow{4}{*}{$\begin{array}{l}* * * \\
* * *\end{array}$} \\
\hline & $2-10$ & 255 & 189 & 214 & 206 & 184 & \\
\hline & $14-26$ & 316 & 235 & 240 & 223 & 198 & \\
\hline & $30-46$ & 293 & 214 & 207 & 197 & 179 & \\
\hline \multirow{4}{*}{$\begin{array}{l}\text { FFA } \\
(\mathrm{mEq} / l)\end{array}$} & pre- & 0.36 & 0.38 & 0.33 & 0.26 & 0.29 & \multirow{4}{*}{$\begin{array}{l}* \\
* \\
*\end{array}$} \\
\hline & $2-10$ & 0.32 & 0.20 & 0.26 & 0.23 & 0.20 & \\
\hline & $14-26$ & 0.19 & 0.19 & 0.18 & 0.17 & 0.13 & \\
\hline & $30-46$ & 0.19 & 0.19 & 0.20 & 0.17 & 0.13 & \\
\hline
\end{tabular}

1) Significant difference among lactation numbers $(* \mathrm{P}<0.05, * * \mathrm{P}<0.01$, and *****P $<0.001$ ).

れ，血獎の乳酸濃度が低下したと考完られる。

分婏前から泌乳初期にか忖て FFA 濃度の高いことは

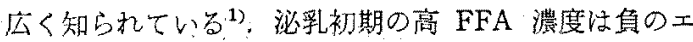
ネルギー出納にともなう蓄積脂肪動員に深く関係あると

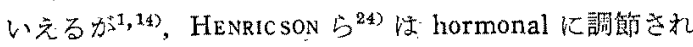
る脂肪動員も考光，エホルギー要求が理論的に満たされ ても脂肪動員が䒕進する可能性を示唆している. 分婏前 の FFA 濃度上昇は胎児発育にともなって消化管が压迫 され採食量加减尚ためと女考光られるが，近年，娃娠末 期における脂質代謝の著しい变化が明らかにされてき だ、寸なかち娃娠末期から蓄皘脂肪の分解・動員など 脂肪組織での買化的な代謝が活発化するといわれる゙。
$\mathrm{METZ}$ and $\mathrm{BERGH}^{25)}$ b姫娠末期の乳牛ではノルアドレナ リン誘発性の脂肪動員の六進すること学報告している。 泌乳開始による TG 㗀度の低下上 $\mathrm{T} \cdot \mathrm{Ch}$ 濃度の上异 は古くから知られ，乳脂合成のため血液中から TG が活

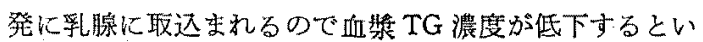
われている ${ }^{26)}$. 脂質は血液中ではリ䖪白として輸送さ れている.リポ蛋白は物理的性質の違いによって力イ ロミクロン, VLDL, LDL や HDL (さらに HDL

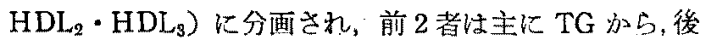
2 者はコレステロール (Ch) やリン脂質から成ってい

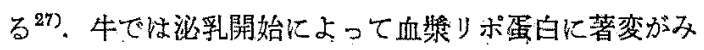

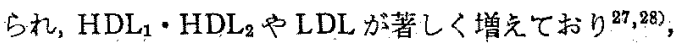


これが泌乳中の Ch 濃度上昇に反映するとい元よう，分

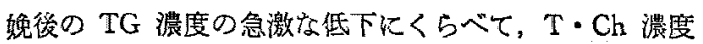
が最高に達するのは分婏の10 週以後であった。泌乳初 期にはりポ蛋白合成能が低いともいわれ299, その活性化 に法遅延が方るかるしれない。

T・Ch 濃度に洔特産次化よる差が明瞭であった。 ヒトでは加龄にともなう $\mathrm{Ch}$ 浱度の上昇は周知の事実で あるが30)，釈牛では産次あるいは年领による血獎脂質浱 度の推移に関寸る情報は少ない，HENRICSON 5 ${ }^{24)}$ によ ると 3 産次の乳牛では初産や 2 産次の牛よりも Ch 賄度 が低いといかれる。しかし Ch 源度に対する遗伝的な影 響は乳牛でも認められ ${ }^{24,31)}$, 今後この点も吟味して研究 する必要があるう。

分婏後に注尿索濃度の低下する例がみられ，ROWLANDS $ら^{12 ｝ \text { も分娩時あるいは分娭後の低下を報告している。 }$

そのような牛では玍料からの蛋白撕取が不足するなどの ため，組織レベルでのアミノ態-N が効率的に利用され ていると考兑られる. また本実駼の 2 産次の牛では泌乳 初期に尿素濃度の低下が持続しており, 繁殖成績の悪か ったことは與味深い。

本研究は当場の「水田高度利用红関する総合研究」の 一部であり，御指導を賜かった一戸次長・本田部長に梁 謝の意定表する。

\section{文献}

1) Bauman, D. E. and W. B. Currie, J. Dairy Sci., 63: 1514-1529. 1980.

2）三輪一智 - 豊田 行康 - 奥田 潤，臨床検查，22: 1232-1261. 1978.

3) Barker, S. B. and W.H. Summerson, J. Biol. Chem, 138: 535-554. 1941.

4) IтAYA, K. and M. U1, J. Lipid. Res., 6: 1620. 1965.

5) Fletcher, M. J. Clin. Chim. Acta., 22: 393397. 1968 .

6）亀野靖郎，踟床検查，22：1262-1272， 1978.

7) 大場康寛・佐々木匡秀 - 谷内典板, 臨床病理, 特 集 22: 12-31, 1975.
8) Hart, I. C., J.A. Bines, C. C. Balch and A.T. Cowle, Life Sci., 16: 1285-1291. 1975.

9) Trenkie, A., J. Dairy Sci., 61: 281-293. 1978.

10) Vasilatos, R. and P. J. Wangsness, J. Nutr., 110: 1479-1487. 1980.

11）上家 哲，日畜会報，47：183-191. 1976,

12) Rowlands, G. J., R. Manston, R. M. Pocock and S. M. Dew, J. Dairy Res., 42: 349-362. 1975.

13) Rowlands, G. J. and R. Manston, Livestock Prod. Sci., 3: 239-256. 1976.

14) Hart, I. C., J. A. Bines, S. V. Morant and J. L. RiduEy, J. Endocr., 77: 333-345. 1978.

15) Hart, I. C., J. A. Bines and S. V. Morant, J. Dairy Sci., 62: 270-279. 1979.

16) Athanasiov, V.N. and R. W. Phillips, Am. J. Vet. Res., 39: 953-956. 1978.

17) Blum, J. W., R. W. Wil SON and D. S. KRONFELd, J. Dairy Sci, 56: 459-464. 1973.

18) Hove, K., Acta Endocr,, 76: 513-524. 1974.

19）佐藤 博，日畜会報，49：333-338，1978.

20) Parker, B. N. J. and R. W. Blowey, Vet. Rec., 98: 394-404. 1976.

21) Blom, A. K, and K. Halse. Acta Endocr., 78: 306-315, 1975.

22）佐藤 博，日畜会報，48：610-616，1977.

23) Baird, G. D., M. A. Lomax, H. W. Symonds and S. R. Shaw, Biochem. J., 186: 47-57. 1980.

24) Henricson, B., G. Jönsson and B. Pehrson, Zbl. Vet. Med., 24: 89-102. 1977.

25) Merz, S. H. M. and S. G. van-den Bergh, Neth. J. Agric Sci., 25: 198-211. 1977.

26) Varman, P. N. and L. H. Schultz, J. Dairy Sci., 51: 1971-1974. 1968.

27) Puppione, D. L., J. Dairy Sci., 61: 651-659. 1978.

28) Raphael, B. G., P. S. Dimick and D. L. Pupplone, J. Dairy Sci., 56: 1025-1032. 1973.

29) Reid, I. M., Exp. Molec. Path., 18: 316-330. 1973. cited by DaLE, H., L. VIK-Mo and P. Fjellheim. Nord. Vet. Med., 31: 97-105. 1979.

30）荻野耕一, 日本臨床，31: 1361-1370，1973.

31) Edfors-Lil ja, I., B. Gahne, K. Lundström, K. Darelius and L. E. Edgvist, Swedish J. Agric. Res, 8: 113-122. 1978. 


\title{
Changes in Plasma Glucose, Lactate, Lipids and Urea Levels during Lactation Period in Dairy Cows
}

\author{
Hiroshi Sato, Shogo Hanasaka and Teruhisa Imamura \\ Tohoku National Agricultural Experiment Station, \\ Morioka-shi 020-01.
}

In 24 dairy cows of 1 st-6 th lactation, blood samples were taken at prepartum, 2 weeks postpartum and thereafter 4 weeks' intervals till dry off. Plasma glucose, lactate, free fatty acid (FFA), triglyceride $(\mathrm{TG})$, total cholesterol $(\mathrm{T} \cdot \mathrm{Ch})$ and urea levels were determined, and their postpartum changes and those differences among cows' lactation numbers were estimated. Plasma glucose level was considerably constant during the early and mid-lactation period, except transient decrease at 2 weeks postpartum in some cows, then it showed to increase during the late: lactation period in many cows. Plasma FFA level at prepartum and early stage after calving was. higher than thereafter. Plasma TG level decreased abruptly after calving, and its level during. lactation period was apparently lower than the prepartum level. After calving, plasma $\mathrm{T} \cdot \mathrm{Ch}$ level increased progressively to maximum one at 10-18 weeks postpartum, and high level was maintained till dry off. Plasma $\mathrm{T}$ - Ch level during the mid-and late lactation period in the cow of 1 st lactation was significantly higher than that of 2 nd -6 th lactation. At the early stage of lactation, plasma lactate and urea levels showed to decrease in many cases. Milk yield was. higher in the cows of 3 rd and 4 th lactation than in the other cows.

Jpn. J. Zootech. Sci., $52(9): 653-658,1981$ 